\title{
Gender differences in aggression of borderline personality disorder
}

\author{
Falk Mancke* ${ }^{*}$ Katja Bertsch and Sabine C Herpertz
}

\begin{abstract}
Aggression is a core feature of borderline personality disorder (BPD). Well-replicated results from the general population indicate that men engage in aggression more frequently than women. This article addresses the question of whether gender also influences aggression in BPD, and whether the neurobiological mechanisms underlying aggressive behavior differ between male and female BPD patients. Data show that most self-reports, interviews and behavioral tasks investigating samples of BPD patients do not find enhanced aggressiveness in male patients, suggesting that BPD attenuates rather than aggravates gender differences usually present in the general population. Neurobiological studies comparing BPD patients with gender-matched healthy controls, however, reveal a number of interesting gender differences: On the one hand, there are well-replicated findings of reduced amygdala and hippocampal gray matter volumes in female BPD patients, while these findings are not shared by male patients with BPD. On the other hand, only male BPD patients exhibit reduced gray matter volume of the anterior cingulate cortex, increased gray matter volume of the putamen, reduced striatal activity during an aggression task, and a more pronounced deficit in central serotonergic responsivity. These neurobiological findings point to a particular importance of impulsivity for the aggression of male BPD patients. Limitations include the need to control for confounding influences of comorbidities, particularly as male BPD patients have been consistently found to show higher percentages of aggression-predisposing comorbid disorders, such as antisocial personality disorder, than female BPD patients. In the future, studies which include systematic comparisons between females and males are warranted in order to disentangle gender differences in aggression of BPD patients with the aim of establishing gender-sensitive treatments where needed.
\end{abstract}

Keywords: Borderline personality disorder, Aggression, Gender differences, Neurobiology

\section{Background}

Aggression may be defined as any behavior directed toward another individual with the intention to cause harm [1]. Dysregulated anger and its behavioral manifestations such as physical fights are among the defining criteria of borderline personality disorder (BPD) [2]. Several findings emphasize the high prevalence of aggression in BPD: $73 \%$ of BPD patients have engaged in aggressive behavior over the course of a year [3], 58\% are "occasionally or often" involved in physical fights, and $25 \%$ have used a weapon against others ([2], p.154). BPD patients constitute a major proportion of prison inmates, with prevalence rates of 30\% [4]. Increased aggression in BPD has been found using both categorical [5-7] and dimensional

\footnotetext{
* Correspondence: falk.mancke@med.uni-heidelberg.de

Department of General Psychiatry, University of Heidelberg, Heidelberg,
} Germany

\section{Biomed Central}

measurements [8-11] of BPD symptomatology, and may thus be regarded as a core feature of the disorder [12,13].

In the general population, men engage in aggression more frequently than women, with effect sizes ranging between $0.14-0.84$ (weighted $d$ ) depending on the method of data collection and the form of aggressive behavior: The effect size is stronger in real-world settings and varies as a function of the seriousness of the aggressive act, i.e., the more dangerous the behavior, the stronger the male preponderance $[14,15]$. However, it remains unclear whether and how gender influences aggression in BPD. In the current article, we will first analyze whether female and male BPD patients differ in their propensity to behave aggressively by reviewing data from self-reports, interviews and behavioral tasks. Second, we will analyze gender differences in the neurobiological underpinnings of BPD patients' aggression. 


\section{Review}

\section{Self-reports, interviews and behavioral tasks}

Self-report measures, such as the Buss-Durkee Hostility Inventory [16] and its revised form, the Buss and Perry Aggression Questionnaire [17], have been used to assess trait aggressiveness by asking about aggressive behaviors and aggression-predisposing emotional experiences, such as intense anger. In the context of intimate partner aggression, the most frequently used questionnaire is the Revised Conflict Tactics Scale [18]. Semi-structured interviews that measure aggression have focused on the quantification of observable and direct aggressive behaviors, e.g., shouting and fighting. These interviews differ in terms of the length of the investigated timespan, measuring aggression either across the lifetime [the BrownGoodwin Lifetime History of Aggression interview [19] and its revised form, the Life History of Aggression interview [20]], or in the last two weeks [the Modified Overt Aggression Scale [21]]. Semi-structured interviews based on classifications of mental disorders, like the Structured Clinical Interview for DSM Disorders [22], do not directly measure aggression, but can nevertheless provide valuable insights as they assess the frequency of aggressionpredisposing-disorders such as antisocial personality disorder (ASPD). The most frequently used behavioral task to measure aggressive behavior in BPD is the Point Subtraction Aggression Paradigm (PSAP) [23,24]. The PSAP uses interpersonal provocation, i.e., the subtraction by a fictitious opponent of "points" worth money that the participant has accumulated during testing. Ignoring the provocation and thereby accumulating points is considered as the "monetary-reinforced response", while reacting in a retaliatory manner by subtracting points from the fictitious opponent - without garnering anything - is considered as the "aggressive response" and is used as the measure of aggression (see, e.g., [25], for a detailed description of the PSAP). The following section reviews gender differences in BPD from studies using these instruments. Table 1 provides a detailed description of the cited studies, including sample characteristics, methodology and key findings.

Using the Brown-Goodwin Lifetime History to measure aggression in BPD patients, some $[26,27]$ but not all [28] studies reported enhanced aggression in the male compared to female patients. Data from studies applying the Buss-Durkee Hostility Inventory are inconsistent: One study using this instrument [26] found more aggression in male than in female BPD patients, while another study did not [29]. No differences between male and female BPD patients were found in studies using the Buss and Perry Aggression Questionnaire [6], the Modified Overt Aggression Scale [29], and the Life History of Aggression [4, personal communication]. The Modified Overt Aggression Scale was also applied in a study by Silberschmidt and coworkers [30]. This study is remarkable for its large sample size particularly with regard to male subjects (559 female and 211 male BPD patients) [30]. However, despite adequate statistical power, no difference between male and female BPD patients emerged. Instead, this study revealed enhanced hostility of female compared to male patients. More recently, Scott and colleagues [31] performed a prospective study in a mixed clinical and community sample and used the Revised Conflict Tactics Scale as a measure for aggressiveness. They also demonstrated that the relationship between BPD traits and aggression was not influenced by gender. This is consistent to the findings of another longitudinal study in which no gender differences were found in a threefold aggression measurement consisting of arrest records, collateral informants, and patient self-reports [3].

When evaluating these results, the sample characteristics of the respective studies need to be taken into account: All of the patients in the study of New et al. [29] suffered from comorbid intermittent-explosive disorder. Additionally, roughly one third of the BPD patients in the cited studies (specifically: $26 \%$ in [27], 24.2\% in [28], $31.5 \%$ in [6], 26\% in [29], and $33 \%$ in [3]) fulfilled the criteria of ASPD. Although gender ratios in comorbid ASPD are not consistently reported, this high amount of comorbidities with other aggression-predisposing disorders limits the ability to draw BPD-specific conclusions and warrants caution when interpreting the results.

A considerable amount of research has analyzed the impact of BPD symptoms on intimate partner violence. Holtzworth-Munroe and Stuart [27,28], for instance, identified the so-called "borderline-dysphoric batterer", characterized by moodiness, fear of abandonment, and insecure attachment patterns, which was related to intimate partner aggression by men against women. In a related vein, Tragesser and Benfield [34] demonstrated that the mate retention tactic of emotional manipulation (e.g., telling one's partner that you are dependent on him or her, that you need him or her) - a tactic which predicted intimate partner aggression in previous research [34] - was positively associated with BPD traits among men but not among women.

Research on intimate partner violence has traditionally focused on male subjects. However, recent crossgender analyses also point towards an influence of BPD on female-to-male intimate partner violence. In a study with more than 14,000 male and female students BPD traits were associated with intimate partner violence (measured with the Revised Conflict Tactics Scale) not only in male, but also in female students [8]. Using the same instrument, another study found a positive relationship between BPD traits and intimate partner aggression in female, but not in male participants of a late-middle-aged community sample [35]. The latter finding might have been due to the form of aggressive 
Table 1 Studies investigating aggression in $\$$ and $\sigma^{7}$ BPD patients using self-reports, interviews and behavioral tasks

\begin{tabular}{|c|c|c|c|c|}
\hline First author & Year & Sample & Methodology & Key findings \\
\hline \multirow[t]{2}{*}{ Banzhaff et al. } & \multirow[t]{2}{*}{2012} & \multirow[t]{2}{*}{170 BPD patients $(114$ +, 56 ぶ) } & $\begin{array}{l}\text { BPD: Structured Clinical Interview for DSM-IV for } \\
\text { personality disorders (SCID-II) }\end{array}$ & \multirow{2}{*}{ 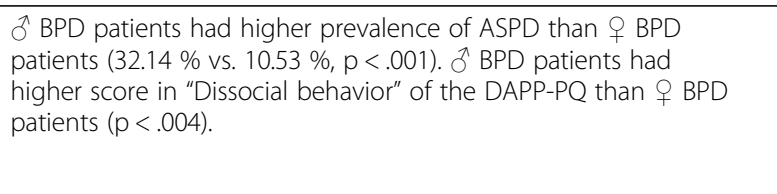 } \\
\hline & & & $\begin{array}{l}\text { Aggression: Subscale Dissocial behavior of the } \\
\text { Dimensional Assessment of Personality Profile } \\
\text { Basic questionnaire (DAPP-BQ) }\end{array}$ & \\
\hline Barrachina et al. & 2011 & 484 BPD patients (402 +, 82 ぶ) & $\begin{array}{l}\text { BPD: SCID II, Diagnostic Interview for Borderlines- } \\
\text { Revised (DIB-R) }\end{array}$ & $\begin{array}{l}\text { O BPD patients had higher prevalence of ASPD than } q \text { BPD patients } \\
(22 \% \text { vs. } 8.2 \%, p<.008) \text {. }\end{array}$ \\
\hline Black et al. & 2007 & $\begin{array}{l}220 \text { offenders newly committed } \\
\text { to prison }(198 \lesssim, 22 \text { ㅇ) }\end{array}$ & $\begin{array}{l}\text { BPD: Structured Interview for DSM-IV Personality } \\
\text { (SIDP-IV) }\end{array}$ & $\begin{array}{l}65 \text { offenders }(29.5 \%) \text { met criteria for BPD. More women (54.5\%) than } \\
\text { men (26.8\%) met criteria for BPD }(p=.007) \text {. }\end{array}$ \\
\hline \multirow[t]{2}{*}{ Brambilla } & \multirow[t]{2}{*}{2004} & \multirow{2}{*}{$\begin{array}{l}10 \mathrm{BPD} \text { patients }\left(\left(6 \%, 4 \delta^{\pi}\right)\right. \\
20 \mathrm{HC} \text { (gender ratio: } \mathrm{n} / \mathrm{a})\end{array}$} & BPD: IPDE & \multirow{2}{*}{$\begin{array}{l}\text { BPD showed higher volume of the putamen }(p=.002) \text { compared } \\
\text { with HC. }\end{array}$} \\
\hline & & & Neuroimaging: stMRI, manual tracing & \\
\hline \multirow[t]{2}{*}{ Costa et al. } & \multirow[t]{2}{*}{2008} & \multirow{2}{*}{$\begin{array}{l}130 \text { intimate aggressive } \hat{\jmath}, 48 \\
\text { non aggressive } \hat{\jmath}\end{array}$} & BPD: Millon Clinical Multiaxial Inventory-III & \multirow{2}{*}{$\begin{array}{l}\text { Jealousy correlated positively with BPD symptomatology } \\
(r=.13, p<.05) \text {. }\end{array}$} \\
\hline & & & $\begin{array}{l}\text { Intimate partner aggression: Revised conflict } \\
\text { tactics scale (CTS2), General Violence Questionnaire }\end{array}$ & \\
\hline Grant et al. & 2008 & $\begin{array}{l}2004 \text { BPD patients (gender } \\
\text { distribution not mentioned) }\end{array}$ & $\begin{array}{l}\text { BPD: Alcohol Use Disorder and Associated } \\
\text { Disabilities Interview Schedule DSM-IV Version }\end{array}$ & $\begin{array}{l}\text { O BPD patients had higher prevalence of ASPD than } 9 \text { BPD patients } \\
(19.4 \% \text { vs. } 9 \%, p<.001) \text {. }\end{array}$ \\
\hline Grilo et al. & 2002 & 100 BPD patients $(69$ \%, 31 ठै) & $\begin{array}{l}\text { BPD: Diagnostic Interview for DSM-IV Personality } \\
\text { Disorders (DIPD-IV) }\end{array}$ & $\begin{array}{l}\text { O BPD patients had higher prevalence of ASPD than } q \text { BPD patients } \\
(48 \% \text { vs. } 0 \%) \text {. }\end{array}$ \\
\hline \multirow[t]{2}{*}{ Hines et al. } & \multirow[t]{2}{*}{2008} & \multirow{2}{*}{ 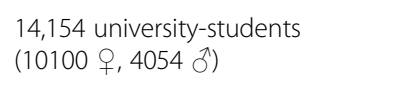 } & BPD: Personal and Relationships Profile & \multirow{2}{*}{$\begin{array}{l}\text { No BPD } \times \text { gender interaction for physical, psychological and sexual } \\
\text { intimate partner aggression ( } p>.05 \text { for all contrasts). }\end{array}$} \\
\hline & & & Intimate partner aggression: CTS2 & \\
\hline \multirow[t]{2}{*}{ Holtzworth et al. } & \multirow[t]{2}{*}{2000} & \multirow{2}{*}{$\begin{array}{l}102 \text { intimate aggressive } \hat{0}, 62 \\
\text { non aggressive } \hat{\jmath}\end{array}$} & BPD: Millon Clinical Multiaxial Inventory-III & \multirow{2}{*}{$\begin{array}{l}\text { Identified four clusters of violent men, among them the so-called } \\
\text { borderline-dysphoric men characterized by high measures on } \\
\text { dependency, jealousy, impulsivity and hostility towards women. }\end{array}$} \\
\hline & & & $\begin{array}{l}\text { Intimate partner aggression: CTS2, Generality of } \\
\text { Violence Questionnaire }\end{array}$ & \\
\hline Johnson et al. & 2003 & 240 BPD patients $(175$ +, 65 ぶ) & BPD: DIPD-IV & $\begin{array}{l}\text { A BPD patients had higher prevalence of ASPD than } q \text { BPD patients } \\
(29.7 \% \text { vs. } 10.3 \%, p<.0001) \text {. }\end{array}$ \\
\hline \multirow[t]{4}{*}{ McCloskey et al. } & \multirow[t]{4}{*}{2009} & \multirow{4}{*}{ 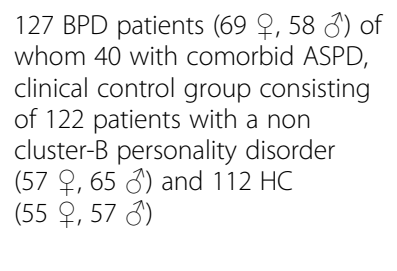 } & \multirow{2}{*}{$\begin{array}{l}\text { BPD: Structured Interview for DSM-IV Personality } \\
\text { (SIDP-IV) }\end{array}$} & No group $x$ gender interaction in the AQ (Wilks $F<1)$. \\
\hline & & & & \multirow{2}{*}{$\begin{array}{l}\text { No difference between } \widehat{\delta} \text { and } q \text { BPD patients in the post-hoc } \\
\text { analysis of the LHA }(p<.01 \text {, based on personal communication). } \\
q \text { BPD patients were more self-aggressive than the } \widehat{\jmath} \text { BPD patients } \\
(p<.01)\end{array}$} \\
\hline & & & $\begin{array}{l}\text { Aggression: Life History of Aggression (LHA), } \\
\text { Aggression Questionnaire (AQ), Point Subtraction } \\
\text { Aggression Paradigm (PSAP) }\end{array}$ & \\
\hline & & & & $\begin{array}{l}\text { No effect of gender or gender } x \text { group interaction in the PSAP } \\
\text { (Wilks } F<1 \text { ). }\end{array}$ \\
\hline McCormick et al. & 2007 & 163 BPD patients (138 +, 25 ぶ) & BPD: SIDP-IV & $\begin{array}{l}3 \text { BPD patients had higher prevalence of ASPD than } q \text { BPD patients } \\
(40 \% \text { vs. } 21 \%, p<.03) \text {. }\end{array}$ \\
\hline \multirow[t]{2}{*}{ Newhill et al. } & \multirow[t]{2}{*}{2009} & \multirow[t]{2}{*}{220 BPD patients $(116$ ○, 104 ぶ) } & $\begin{array}{l}\text { BPD: Structured Interview for DSM-III-R } \\
\text { Personality }\end{array}$ & \multirow[t]{2}{*}{ No gender difference in aggression of BPD patients $(p=.342)$} \\
\hline & & & $\begin{array}{l}\text { Aggression: arrest records, collateral reports, } \\
\text { patients report using behaviors adapted from } \\
\text { the CTS2 }\end{array}$ & \\
\hline
\end{tabular}


Table 1 Studies investigating aggression in $\$$ and $\sigma^{\top}$ BPD patients using self-reports, interviews and behavioral tasks (Continued)

\begin{tabular}{|c|c|c|c|c|}
\hline \multirow[t]{2}{*}{ Prehn et al. } & \multirow[t]{2}{*}{2013} & \multirow[t]{2}{*}{$15 \hat{\jmath}$ BPD-ASPD, $17 \hat{\jmath} \mathrm{HC}$} & BPD: IPDE & \multirow{2}{*}{$\begin{array}{l}\text { BPD-ASPD displayed increased amygdala activity exclusively in } \\
\text { response to high, but not neutral and low emotional stimuli when } \\
\text { compared to } \widehat{A} \mathrm{HC} \text {. }\end{array}$} \\
\hline & & & $\begin{array}{l}\text { Neuroimaging: fMRI during presentation of } \\
\text { emotional \& neutral pictures }\end{array}$ & \\
\hline \multirow[t]{2}{*}{ Ross et al. } & \multirow[t]{2}{*}{2009} & \multirow{2}{*}{$\begin{array}{l}124 \text { intimate aggressive } 0 \\
(7 \text { BPD patients, } 16 \text { BPD-ASPD, } 18 \\
\text { ASPD patients and } 83 \text { subjects } \\
\text { without a personality disorder) }\end{array}$} & BPD: SCID-II & \multirow{2}{*}{$\begin{array}{l}\text { o BPD-ASPD were more likely than ASPD-patients }(p<.01) \text { and } \\
\text { subjects without a personality disorder }(p<.01) \text { to react aggressively } \\
\text { upon women's displays of stress. }\end{array}$} \\
\hline & & & Intimate partner aggression: CTS2 & \\
\hline \multirow[t]{2}{*}{ Scott et al., } & \multirow[t]{2}{*}{2014} & \multirow[t]{2}{*}{$\begin{array}{l}75 \text { psychiatric outpatients and } 75 \\
\text { community residents }(98+92,32)\end{array}$} & $\begin{array}{l}\text { BPD: dimensional score using a Diagnostic and } \\
\text { Statistical Manual of Mental Disorders checklist and } \\
\text { the Structured Interview for DSM-IV Personality }\end{array}$ & \multirow[t]{2}{*}{ Gender did not influence the prediction of BPD on aggression. } \\
\hline & & & Aggression: Revised Conflict Tactics Scale & \\
\hline \multirow[t]{3}{*}{ Silberschmidt et al. } & \multirow[t]{3}{*}{2015} & \multirow[t]{3}{*}{770 BPD $(559$ ๆ, 211 ठै) } & BPD: DIPD-IV & \multirow{3}{*}{$\begin{array}{l}\text { No gender difference in aggression of BPD patients }(p=.193) \text {. क BPD } \\
\text { patients showed enhanced hostility than the } \hat{\delta} \text { BPD }(p=.011) \text {. }\end{array}$} \\
\hline & & & Aggression: OAS-M & \\
\hline & & & Hostility: The Symptom Checklist 90 Revised & \\
\hline Tadic et al. & 2009 & $159(110$ q, 49 ठૈ) & BPD: SCID-II & $\begin{array}{l}\text { O BPD patients had higher prevalence of ASPD and higher prevalence } \\
\text { of the criterion intensive anger }(73.5 \% \text { vs } 49.1 \%, p<.001) \text { than }+ \\
\text { BPD patients }(57.1 \% \text { vs. } 25.51 \%, p<.001) \text {. }\end{array}$ \\
\hline \multirow[t]{2}{*}{ Weinstein et al. } & \multirow[t]{2}{*}{2012} & \multirow[t]{2}{*}{$\begin{array}{l}847 \text { late middle-age (55-64) } \\
\text { adults }\left(347+9,500 \delta^{(1)} \text { from a }\right. \\
\text { community sample }\end{array}$} & $\begin{array}{l}\text { BPD: SIDP-IV, Multi-Source Assessment of Personality } \\
\text { Pathology (MAPP) fulfilled by the participant and an } \\
\text { informant }\end{array}$ & \multirow[t]{2}{*}{$\begin{array}{l}\text { In } 9, \text { but not } 0 \text {, subjects intimate partner aggression was related to } \\
\text { BPD traits (regression-coefficients: } 37.5 \text { for the SIDP-IV, } 10.2 \text { for the } \\
\text { self-MAPP and } 8.9 \text { for the informant-MAPP). }\end{array}$} \\
\hline & & & Intimate partner aggression: CTS2 & \\
\hline Zanarini et al. & 1998 & 379 BPD patients (296 ㅇ, 83 ふૈ) & $\begin{array}{l}\text { BPD: Diagnostic Interview for DSM-III-R Personality } \\
\text { Disorders, DIB-R }\end{array}$ & $\begin{array}{l}\text { O BPD patients had higher prevalence of ASPD than } q \text { BPD patients } \\
\text { (48 \% vs. } 16 \%, p<.00001) \text {. }\end{array}$ \\
\hline Zlotnick et al. & 2003 & 149 BPD patients (104 ㅇ, 45 ぶ) & BPD: SIDP-IV & $\begin{array}{l}\text { O BPD patients had higher prevalence of ASPD than } q \text { BPD patients } \\
(38.6 \% \text { vs. } 11.4 \%, p<.001) \text {. }\end{array}$ \\
\hline
\end{tabular}

The studies are listed in alphabetical order based on the author's first name.

Abbreviations: AQ: Aggression Questionnaire, BG-LHA: Brown-Goodwin Lifetime History of aggression, BDHI: Buss-Durkee Hostility Inventory, DIB-R: Diagnostic Interview for Borderlines- Revised, CTS2: Revised conflict tactics scale, DAPP-BQ: Dimensional Assessment of Personality Profile Basic questionnaire, IPDE: International Personality Disorders Examination, LHA: Life History of Aggression, MAPP: Multi-Source Assessment of Personality Pathology, m SCID-II: Structured Clinical Interview for DSM-IV Axis II Personality Disorders, OAS-M: modified Overt Aggression Scale SIDP-IV: Structured Interview for DSM-IV Personality. 
behavior examined: It consisted mostly of verbal aggression, e.g., shouting at the partner, and this form of aggression has previously been shown to be associated with a reduced gender difference in the male direction in the general population [15].

Although self-aggressive behavior has often been considered as distinct from aggression directed towards other individuals, aggression measurements, such as the Life History of Aggression interview, frequently include subscales for self-aggressive behavior. Female BPD patients have been found to report more self-aggressive acts than their male counterparts in the Life History of Aggression interview [4, personal communication]. Similar to the female-only association between BPD traits and verbal aggression reported above, this finding marks the importance of considering the specific characteristics of the studied behavior when evaluating gender differences in aggression.

Several studies using semi-structured interviews investigated whether male and female BPD patients differ in the prevalence of comorbid disorders that predispose them to aggression, such as ASPD. Male BPD patients were more frequently found to meet the diagnostic criteria of ASPD than female patients, irrespective of whether symptomatology was assessed dimensionally [36] or categorically [37-44]. On the level of DSM-IV criteria, one study [40] found that male compared to female BPD patients more often fulfilled the criterion of intensive anger, while this was not found in another study [39].

Studies have repeatedly found more aggressive responses on the PSAP in patients with BPD compared to healthy individuals $[6,29,45]$. However, male and female BPD patients did not differ in their aggressive responses $[6,29]$. Instead, a gender difference was found in what is considered to be the "monetary-reinforced response" (for details, see above): Male controls chose this response more often, thereby garnering more points at the end of the task, than the male BPD patients. The opposite pattern was observed for the women: Female BPD patients chose the "monetary-reinforced response" more frequently than female controls, which - although counterintuitive - suggests enhanced behavioral control of female BPD patients compared to female controls. However, both studies using the PSAP did not report any gender effect in healthy controls; this result has to be interpreted in the context of the type of provocation used by the PSAP. It uses interpersonal frustration, which has been associated with a smaller gender difference in aggression in healthy samples [46].

Taken together, results from self-report and interviewbased measurements and behavioral tasks in BPD patients show a different pattern than in the general population. In the general population, men have been found to engage in more aggression than women, whereas in BPD, most studies did not find such a gender difference in aggression. Findings reporting more verbal aggression in female subjects scoring high on BPD traits than their male counterparts emphasize the importance of differentiating between specific forms of aggression. Male BPD patients have been consistently found to show higher percentages of aggression-predisposing disorders such as ASPD. Research on intimate partner aggression has concentrated on male-to-female aggression and indicates a predisposing effect of BPD on intimate partner aggression, which might stem from different mate retention tactics. However, as the number of studies is limited, and as results are often confounded by comorbidity and grouping together of different forms of aggression, further research is urgently needed.

\section{Neurobiology}

Aggressive behavior is understood to result from biological as well as environmental vulnerabilities (see, e.g., [47] for a review). Environmental risk factors are numerous and include maltreatment, smoking during pregnancy, divorce, peer deviance, parental psychopathology, social disadvantage, and coercive discipline [48]. The latter is thought to establish reinforcement contingencies that shape and maintain deviant and aggressive behaviors $[49,50]$. Theories on the biological underpinnings of aggression in BPD propose a brain circuitry implicating predominantly prefrontal and limbic structures. More specifically, a model has been proposed in which prefrontal regions, especially the orbital frontal cortex and the anterior cingulate cortex, fail to control enhanced reactivity of limbic regions such as the amygdala [see, e.g., 43, for a review]. The insufficiency of prefrontal regions in regulating limbic hyperactivity has been consistently related to deficiency of the prefrontal serotonergic system [52]. This prefrontal-limbic imbalance was shown to be associated with BPD patients' propensity to perceive emotionally challenging stimuli as provocative and threatening, and thus favoring anger and ultimately aggressive behavior [51,53]. Brain areas additionally modulating the aggressive response include hippocampal [54] and hypothalamic structures $[54,55]$.

The interaction between environmental and biological factors is rather synergistic than additive (see, e. g., [56] for a review). For instance, in the landmark paper of Caspi et al. [57], the vulnerable genotype alone explained less than $1 \%$ of the variance in antisocial behaviors, including aggression. However, in combination with maltreatment its fraction of explained variance rose to $65 \%$. The moderation of gene $x$ environment interactions by gender may therefore be a highly interesting topic for future research.

In the following paragraph, we will evaluate gender differences in the neurobiological systems underlying 
BPD patients' aggression. Table 2 provides a detailed description of the cited studies, including sample characteristics, methodology, and key findings.

BPD patients were found to show gender differences in brain volume: When compared to gender-matched healthy controls, female but not male patients displayed reduced gray matter volumes in the amygdala and hippocampus, while male but not female BPD patients showed reduced volume in the anterior cingulate cortex as well as increased volume in the right putamen [27]. This study did not, however, report a comparison between men and women with BPD. Other mixed-gender studies that included a notably large number of male BPD patients - but which did not perform direct gender comparisons - also reported reduced volume in the anterior cingulate cortex [50 with $54 \%$ male BPD patients, 51 with $58 \%$ male BPD patients] and increased volume in the putamen [52 with $40 \%$ male BPD patients], which provides tentative support for the male-only findings in the study by Soloff et al. [27].

Studies investigating only male BPD patients compared to healthy men revealed volume reductions in the orbital frontal cortex and the ventromedial prefrontal cortex [61] as well as in the superior, medial and middle frontal gyrus [62]. Again, comorbidities need to be considered here: $58.3 \%$ of the male BPD patients but only $9.1 \%$ of the female BPD patients in the study by Soloff et al. [27], and all the participants in the work by Bertsch et al. [61], were diagnosed with ASPD, which limits the ability to interpret BPD-specific effects.

Recently, it was found that while performing the PSAP, male BPD patients with comorbid intermittent explosive disorder had a significantly lower glucose metabolism rate in the striatum (a subcortical brain structure consisting of the caudate nucleus and the putamen) than female patients [63]. No difference was found between female patients and healthy women. Notably, to date, this is one of the few neuroimaging studies to have allowed the direct comparison of male with female BPD patients. The striatum is closely connected with prefrontal areas [64] and one of its suggested roles is to recognize the situational context the organism is in $[65,66]$. Reduced striatal activity in male BPD patients could therefore be associated with inadequate evaluation of the situational context, which may impair inhibitory processes of prefrontal areas and might ultimately facilitate aggressive behavior. This functional neuroimaging finding shown only in male BPD patients parallels the above-mentioned structural neuroimaging alteration of the putamen. Future studies could pursue the highly interesting question of whether striatal brain structures may be a primary correlate of gender differences in aggression of BPD patients.

Interestingly, in a previous analysis of the same data by Perez-Rodriguez and colleagues [63], no gender differences in brain metabolism were found in prefrontal and amygdala areas while participants were performing the PSAP [29]. This is of interest since a positron emission tomography study by Soloff et al. [67] reported prefrontal hypometabolism during baseline condition for female but not male BPD patients when a gendermatched analysis was performed.

Functional neuroimaging studies that analyzed only male BPD patients with comorbid ASPD found increased amygdala activity exclusively in response to high, but not to neutral and low emotionally salient stimuli [68]. This is in contrast to female BPD patients, who also displayed enhanced amygdala reactivity to neutral stimuli compared to healthy women [69]. Both Prehn et al. [68] and Niedtfeld et al. [69] used stimulation material from the International Affective Picture System [70]. However, comparability between the two studies is limited, as Prehn et al. [68] presented the pictures as taskirrelevant background distractors in a working memory task, while the pictures were task-relevant and therefore in the participants' attentional focus in the study by Niedtfeld et al. [69]. Nevertheless, these results raise the question of different amygdala activity in male versus female BPD patients, which is of particular interest since gender-specific functional [71] and structural [72] differences in the amygdala have been reported in healthy samples.

Neurochemically, the central serotonin system seems to differ substantially between male and female BPD patients. Using d-fenfluramine or $\mathrm{m}$-Chlorophenylpiperazine to test the responsivity of the serotonin system, compared to gender-matched healthy volunteers, only male but not female BPD patients showed a diminished serotonergic response in most $[26,73,74]$ but not all [75] studies. Correlational analyses further showed that only the male patients demonstrated an inverse relationship between measures of aggression (the Buss-Durkee Hostility Inventory) and serotonin responsivity [26]. Additional positron emission tomography in response to d-fenfluramine revealed that male but not female BPD patients displayed decreased glucose uptake relative to gender-matched controls, which was mainly located in the temporal lobe [67]. However, the ability to draw inferences from this study is limited, as it included more than twice as many female as male BPD patients.

Interestingly, a recent study found increased serotonin$2 \mathrm{~A}$ receptor binding in female $\mathrm{BPD}$ patients compared to gender-matched controls and male BPD patients [28], which implies diminished serotonergic agonism of the female patients. Furthermore, binding potentials predicted aggression only in the female patients.

Serotonergic $\mathrm{x}$ environment interactions may additionally be moderated by gender. For instance, the association between the short allele of the serotonin transporter gene 
Table 2 Studies investigating aggression in $\$$ and/or $\sigma^{7}$ BPD patients using neurobiological methods

\begin{tabular}{|c|c|c|c|c|}
\hline First Author & Year & Sample & Methodology & Key findings \\
\hline \multirow[t]{2}{*}{ Bertsch et al. } & \multirow[t]{2}{*}{2013} & \multirow[t]{2}{*}{$\begin{array}{l}39 \text { o BPD patients with comorbid } \\
\text { ASPD (BPD-ASPD), } 14 \mathrm{HC}\end{array}$} & $\begin{array}{l}\text { BPD: International Personaliy Disorder } \\
\text { Examination (IPDE) }\end{array}$ & \multirow{2}{*}{$\begin{array}{l}\text { A BPD-ASPD patients displayed volume reduction in the left frontal pole, left orbital } \\
\text { frontal cortex and right ventromedial prefrontal cortex compared to } \hat{\jmath} \mathrm{HC} \\
\text { (all } \mathrm{p}<.05, \mathrm{ROI} \text {-analysis). }\end{array}$} \\
\hline & & & $\begin{array}{l}\text { Neuroimaging: strucutural magnetic } \\
\text { resonance imaging (stMRI), voxel based } \\
\text { morphometry (VBM) }\end{array}$ & \\
\hline \multirow[t]{2}{*}{ Brambilla } & \multirow[t]{2}{*}{2004} & \multirow{2}{*}{$\begin{array}{l}10 \mathrm{BPD} \text { patients }\left(\left(6 \mathrm{\sigma}, 4 \mathrm{~J}^{\Uparrow}\right), 20 \mathrm{HC}\right. \\
\text { (gender ratio: } \mathrm{n} / \mathrm{a})\end{array}$} & BPD: IPDE & \multirow[t]{2}{*}{ BPD showed higher volume of the putamen $(p=.002)$ compared with $\mathrm{HC}$. } \\
\hline & & & Neuroimaging: stMRI, manual tracing & \\
\hline \multirow[t]{3}{*}{ Coccaro et al. } & \multirow[t]{3}{*}{2007} & \multirow{3}{*}{$\begin{array}{l}31 \text { ô personality-disorders subjects, } \\
\text { including } 4 \text { BPD patients }\end{array}$} & BPD: SCID-II & \multirow{3}{*}{$\begin{array}{l}\text { Testosterone CSF concentration of } \widehat{\lambda} \text { personality disordered patients, including BPD, } \\
\text { is not correlated with aggression }(p=.34) \text {. }\end{array}$} \\
\hline & & & $\begin{array}{l}\text { Aggression: Life History of Aggression } \\
\text { (LHA), criteria for Intermittend Explosive } \\
\text { Disorder }\end{array}$ & \\
\hline & & & $\begin{array}{l}\text { Neurochemistry: Cerebrospinal fluid (CSF) } \\
\text { concentration of testosterone }\end{array}$ & \\
\hline \multirow[t]{3}{*}{ Coccaro et al. } & \multirow[t]{3}{*}{1998} & \multirow{3}{*}{$\begin{array}{l}26 \text { personality-disordered subjects, } \\
\text { including } 7 \text { BPD patients } \\
\left(8 \stackrel{+}{8} 18 \hat{0}^{\prime}\right)\end{array}$} & BPD: According to DSM-IV criteria & \multirow{3}{*}{$\begin{array}{l}\text { In the personality-disordered patients, including BPD, vasopressin CSF concentration } \\
\text { was positively correlated with aggression }(r=.41, p=.04) \text {, which was stronger in } \hat{\sigma}^{\lambda} \\
(r=.65) \text { than in }+ \text { subjects }(r=.27) \text {. }\end{array}$} \\
\hline & & & Aggression: LHA & \\
\hline & & & $\begin{array}{l}\text { Neurochemistry: CSF concentration of } \\
\text { vasopressin }\end{array}$ & \\
\hline \multirow[t]{2}{*}{ Hazlett et al., } & \multirow[t]{2}{*}{2005} & \multirow[t]{2}{*}{ 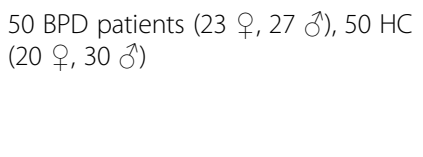 } & $\begin{array}{l}\text { BPD: Structured Interview for DSM-III-R } \\
\text { Personality }\end{array}$ & \multirow[t]{2}{*}{$\begin{array}{l}\text { BPD showed reduced gray matter and more white matter volume in BA } 24 \text { and } 31 \\
\text { of the cingulate compared with } \mathrm{HC} \text { (all } \mathrm{p}<.01, \mathrm{ROI} \text { analysis). }\end{array}$} \\
\hline & & & $\begin{array}{l}\text { Neuroimaging: stMRI, manual } \\
\text { tracing }\end{array}$ & \\
\hline \multirow[t]{2}{*}{ Hollander et al. } & \multirow[t]{2}{*}{1994} & \multirow{2}{*}{ 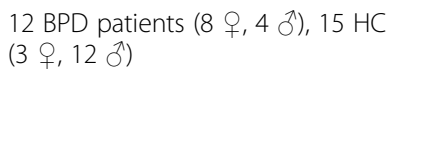 } & BPD: SCID-II & \multirow{2}{*}{$\begin{array}{l}\text { Diminished serotonergic responsivity in } \hat{\sigma}^{2} \text {, but not } q \text { BPD patients compared to } \\
\text { gender-matched HC }(p=.010)\end{array}$} \\
\hline & & & $\begin{array}{l}\text { Neurochemistry: Serotonergic } \\
\text { responsivity via m-chlorophenylpiperazine } \\
\text { (m-CPP) }\end{array}$ & \\
\hline \multirow[t]{2}{*}{ Martial et al. } & \multirow[t]{2}{*}{1997} & \multirow[t]{2}{*}{5 q BPD patients } & BPD: DIB-R & \multirow[t]{2}{*}{ No diminished serotonergic responsivity of $q$ BPD patients. } \\
\hline & & & $\begin{array}{l}\text { Neurochemistry: Serotonergic responsivity } \\
\text { via d-fenfluramine (FEN) }\end{array}$ & \\
\hline \multirow[t]{2}{*}{ Minzenberg } & \multirow[t]{2}{*}{2008} & \multirow[t]{2}{*}{ 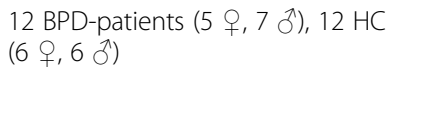 } & $\begin{array}{l}\text { BPD: Structured Interview for DSM-IV } \\
\text { Personality }\end{array}$ & \multirow[t]{2}{*}{$\begin{array}{l}\text { BPD had reduced gray matter volume in the anterior cingulate (BA 24/32) } \\
\text { compared to HC ( } p<.003-007, \text { ROI analysis). }\end{array}$} \\
\hline & & & Neuroimaging: stMRI, VBM & \\
\hline \multirow{3}{*}{$\begin{array}{l}\text { New/Perez- } \\
\text { Rodriguez et al. }\end{array}$} & \multirow{3}{*}{$\begin{array}{l}2009 / \\
2012\end{array}$} & \multirow{3}{*}{ 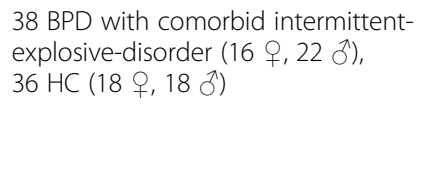 } & BPD: SCID-II & \multirow{3}{*}{ 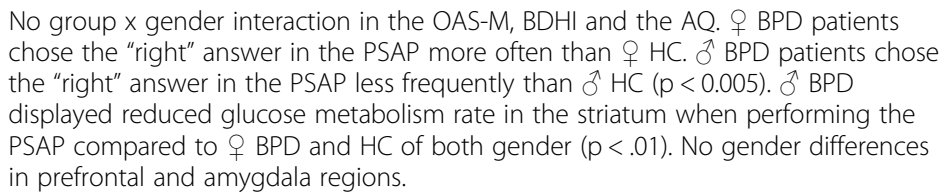 } \\
\hline & & & $\begin{array}{l}\text { Aggression: modified Overt Aggression } \\
\text { Scale (OAS-M), }\end{array}$ & \\
\hline & & & $\begin{array}{l}\text { Buss-Durkee Hostility Inventory (BDHI), } \\
\text { AQ, PSAP }\end{array}$ & \\
\hline
\end{tabular}

Neuroimaging: PET while performing PSAP 
Table 2 Studies investigating aggression in $\$$ and/or $\sigma^{7}$ BPD patients using neurobiological methods (Continued)

\begin{tabular}{|c|c|c|c|c|}
\hline \multirow[t]{2}{*}{ Niedtfeld et al. } & \multirow[t]{2}{*}{2010} & \multirow[t]{2}{*}{23 q BPD patients, 26 \& HC } & $\begin{array}{l}\text { BPD: International Personality Disorders } \\
\text { Examination (IPDE) }\end{array}$ & \multirow[t]{2}{*}{$\begin{array}{l}\text { o BPD patients displayed increased amygdala reactivity in response to neutral and } \\
\text { negative emotional stimuli when compared to } \& \mathrm{HC} \text {. }\end{array}$} \\
\hline & & & $\begin{array}{l}\text { Neuroimaging: functional magnetic resonance } \\
\text { (fMRI) during presentation of emotional \& } \\
\text { neutral pictures }\end{array}$ & \\
\hline \multirow[t]{2}{*}{ Prehn et al. } & \multirow[t]{2}{*}{2013} & \multirow[t]{2}{*}{$15 \widehat{\partial} \mathrm{BPD}-\mathrm{ASPD}, 17 \widehat{\partial} \mathrm{HC}$} & BPD: IPDE & \multirow{2}{*}{$\begin{array}{l}\text { त BPD-ASPD displayed increased amygdala activity exclusively in response to high, } \\
\text { but not neutral and low emotional stimuli when compared to }{ }^{\lambda} \mathrm{HC} \text {. }\end{array}$} \\
\hline & & & $\begin{array}{l}\text { Neuroimaging: fMRI during presentation of } \\
\text { emotional \& neutral pictures }\end{array}$ & \\
\hline \multirow[t]{3}{*}{ Rinne et al. } & \multirow[t]{3}{*}{2000} & \multirow[t]{3}{*}{12 q BPD patients, 9 q $\mathrm{HC}$} & $\begin{array}{l}\text { BPD: Structured Interview for DSM III-R } \\
\text { Personality }\end{array}$ & \multirow[t]{3}{*}{ o BPD patients displayed diminished serotonergic responsivity than $q \mathrm{HC}(\mathrm{p}<.05)$. } \\
\hline & & & Disorders & \\
\hline & & & $\begin{array}{l}\text { Neurochemistry: Serotonergic responsivity } \\
\text { via m-CPP }\end{array}$ & \\
\hline \multirow[t]{3}{*}{ Soloff et al. } & \multirow[t]{3}{*}{2003} & \multirow{3}{*}{$\begin{array}{l}64 \mathrm{BPD} \text { patients }\left(44 \text { }, 20 \delta^{\pi}\right), 57 \\
\mathrm{HC}\left(21 \stackrel{+}{+}, 36 \delta^{\pi}\right)\end{array}$} & BPD: IPDE & \multirow{3}{*}{$\begin{array}{l}\text { A BPD patients showed higher scores in the BDHI }(p=0.03) \text { and the BG-LHA } \\
(p=.002) \text { than the } q \text { BPD patients. } \delta \text {, but not } q, B P D \text { patients, had significantly } \\
\text { lower delta-prl }(p<.02) \text {, peak-prl }(p<.001) \text { and AUC-prl }(p<.003) \text { compared to } \\
\text { gender-matched HC. In } \delta \text {, but not } \uparrow, \text { BPD patients serotonergic responsivity was } \\
\text { inversely correlated with scores of the LHA }(p<.05)\end{array}$} \\
\hline & & & $\begin{array}{l}\text { Aggression: BDHI, Brown-Goodwin Lifetime } \\
\text { History of aggression (BG-LHA) }\end{array}$ & \\
\hline & & & $\begin{array}{l}\text { Neurochemistry: Serotonergic responsivity } \\
\text { via FEN }\end{array}$ & \\
\hline \multirow[t]{3}{*}{ Soloff et al. } & \multirow[t]{3}{*}{2005} & \multirow{3}{*}{ 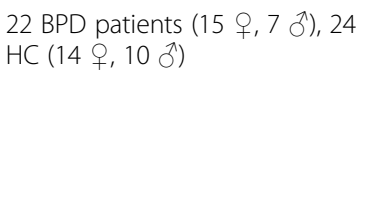 } & BPD: IPDE, DIB-R & \multirow{3}{*}{$\begin{array}{l}\text { }+ \text {, but not } \hat{\delta}, \text { BPD patients displayed reduced glucose metabolism rate in the } \\
\text { prefrontal cortex during baseline condition compared to gender-matched } \mathrm{HC} \\
(\mathrm{p}<.05) \text {. When tested for serotonergic responsivity } \lesssim \text { BPD patients, but not } q \\
\text { BPD patients, showed decreased glucose metabolization in the It. temporal and } \\
\text { frontal lobe }(p<.05)\end{array}$} \\
\hline & & & Aggression: BG-LHA & \\
\hline & & & $\begin{array}{l}\text { Neurochemistry: serotonergic responsivity } \\
\text { via FEN Neuroimaging: PET during baseline } \\
\text { and serotonergic responsivity condition }\end{array}$ & \\
\hline \multirow[t]{3}{*}{ Soloff et al. } & \multirow[t]{3}{*}{2008} & \multirow{3}{*}{ 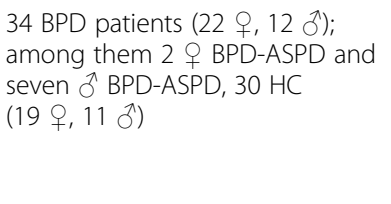 } & BPD: IPDE & \multirow{3}{*}{ 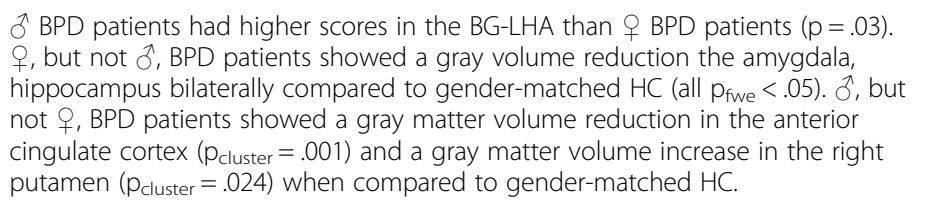 } \\
\hline & & & Aggression: BG-LHA & \\
\hline & & & Neuroimaging: stMRI, VBM & \\
\hline \multirow[t]{2}{*}{ Völlm et al. } & \multirow[t]{2}{*}{2009} & \multirow[t]{2}{*}{$7 \widehat{\delta}$ BPD patients, $6 \hat{\sigma} \mathrm{HC}$} & BPD: SCID-II & \multirow{2}{*}{$\begin{array}{l}\text { O BPD patients showed gray matter volume reduction in the medial, middle and } \\
\text { superior frontal gyrus, bilaterally, and the left orbitofrontal cortex and right anterior } \\
\text { cingulate cortex compared to o } \mathrm{HC} \text { (all at least puncorr. }<.001 \text { ). }\end{array}$} \\
\hline & & & Neuroimaging: stMRI, VBM & \\
\hline
\end{tabular}

The studies are listed in alphabetical order based on the author's first name.

Abbreviations:: BG-LHA: Brown-Goodwin Lifetime History of aggression, BPD-ASPD: BPD patients with comorbid ASPD, BDHI: Buss-Durkee Hostility Inventory, CSF: cerebrospinal fluid, DIB-R: Diagnostic Interview for Borderlines- Revised, International Personality Disorders Examination, fMRl: functional magnetic resonance imaging, LHA: Life History of Aggression, m-CPP: $\mathrm{m}$-chlorophenylpiperazine, PSAP: Point Subtraction Aggression Paradigm SCID-II: Structured Clinical Interview for DSM-IV Axis II Personality Disorders, OAS-M: modified Overt Aggression Scale SIDP-IV: Structured Interview for DSM-IV Personality, stMRI: structural magentic resonance imaging, PET: positron emission tomography, ROl: region of interest, VBM: voxel based morphometry. 
and laboratory measured aggression was more prominent in men than in women [76]. Contrary to this, serotonergic vulnerabilities may primarily lead to self-injurious behavior in women as shown by Crowell and coworkers [77]. These authors investigated the effect of peripheral serotonin and mother-daughter conflict on self-injurious behavior. Taken by themselves, peripheral serotonin and conflict had only limited effect, whereas their interaction explained $64 \%$ of the variance in self-injurious behavior [77]. These results - though not performed with BPD patients - illustrate the complexity of the interplay between the serotonergic system, gender and aggression.

Other neurochemical systems might additionally play a role in the differential regulation of aggression between male and female BPD patients. In a sample of personalitydisordered subjects, including BPD patients, a positive correlation was found between the concentration of vasopressin in the cerebrospinal fluid and aggression, which was stronger in male than in female subjects [78]. Again, due to the small number of BPD patients in this study, interpretability is limited.

In the general population, a weak positive association between concentrations of testosterone in different body fluids (mostly blood or saliva) and antisocial, dominant, or competitive behaviors has been suggested [79]. Testosterone was also found to modulate aggressive behavior, although the direction of the association is less clear $[80,81]$. In a sample of male patients with various personality disorders, including BPD patients, no association between cerebrospinal fluid concentrations of testosterone and aggression was found [82]. Again, the small proportion of BPD patients in this study (4 out of 31) limits the ability to draw BPD-specific conclusions. In line with no effect of testosterone on aggression in BPD patients, one study with female BPD patients did not find an association between free serum testosterone levels and measures of aggression [83]. Plasma concentrations of oxytocin were negatively associated with trait aggressiveness in a sample of female BPD patients [84]; so far, findings from male BPD patients in this respect are lacking.

In sum, results from neurobiological studies suggest a different pattern of alterations between male and female BPD patients. Male but not female BPD patients when compared to gender-matched healthy volunteers exhibited reduced gray matter volume of the anterior cingulate cortex, increased gray matter volume of the putamen, reduced striatal activity during an aggression task, and a more pronounced deficit in central serotonergic responsivity. Specific alterations found in female BPD patients are rare. The few findings that exist raise the question of whether dysfunctions in the amygdala are more pronounced in female than in male BPD patients.

\section{Conclusions}

This article addressed the question of gender differences in BPD patients' aggressive behavior. In the general population, men show enhanced aggression compared with women. By contrast, most results from self-reports, interviews, and behavioral tasks do not indicate any gender differences in the patients' aggressiveness. Taken together, these results suggest that BPD attenuates rather than aggravates the gender difference in aggression normally present in the general population.

This article also reviewed gender differences in the neurobiological underpinnings of BPD patients' aggression. Conclusions from these findings require a conceptual background: Aggression is a multi-faceted social behavior $[1,85]$, which can be regarded as a downstream dysfunctional behavior resulting from core symptoms of BPD [31]. Recently, we proposed a model of aggression in BPD from the perspective of biobehavioral dimensions resp. mechanisms [86] suggesting impulsivity and affect dysregulation to be particularly important biobehavioral dimensions underlying aggressive behavior in BPD.

Within this framework, the findings reviewed above may point to a particular importance of the biobehavioral dimension of impulsivity for male BPD patients' aggressiveness. Most of the neurobiological alterations that have been reported in male but not in female BPD patients in comparison to gender-matched healthy volunteers, namely the volume loss of the anterior cingulate cortex [58,87], the reduced serotonergic responsivity [88] as well as the structural and functional abnormalities of striatal brain structures [89], have been related to reduced impulse control. Additionally, male compared to female BPD patients scored higher on impulsivity [90] (cf. [91]) and explosive temperaments [92]. In line with this are findings from the general population, where the male-over-female preponderance in aggression has also been traced back to higher impulsivity [93] and/or reduced behavioral inhibition [15].

As mentioned above, specific alterations in female BPD patients are rare. Hypothesizing that dysfunctions of the amygdala might be more prominent in female than in male patients, one could speculate that affective dysregulation [94] may play a specific role in female BPD patients' aggressiveness.

The following limitations should be noted. First, studies analyzing mixed-gender samples are scarce. To exclude a potential confounding influence of gender, the majority of the neurobiological mixed-gender studies reported here compared the patients with gender-matched healthy controls, e.g. male BPD patients with male controls. To our knowledge, only two neuroimaging studies $[28,63]$ have directly compared male with female patients. Although the approach to compare BPD patients 
with controls of the same gender primarily seems reasonable to us, it does not enable an understanding to be gained of whether and how the BPD diagnosis interacts with gender. Future studies including sufficiently large gender-mixed samples, which in addition to gendermatched comparisons also compare male and female BPD patients, are therefore requested in order to investigate whether BPD psychopathology impinges differently upon women and men.

Comparing male directly with female BPD patients may also be of importance in terms of gender-specific treatments. For instance, psychopharmacological substances targeting the serotonin system may lead to different effects in male versus female BPD patients. However, the - at least to our knowledge - only study to date to have used the serotonin reuptake inhibitor fluoxetine to treat male and female patients with intermittent explosive disorder, and in part comorbid BPD, did not find a significant drug $x$ gender interaction [95]. Psychotherapeutic treatments might profit from different treatment foci, which consider gender-specific differences in mechanisms underlying aggression in BPD. For instance, male BPD patients may particularly benefit from interventions aiming to increase impulse control, as, e.g., implemented in the Dialectical Behavioral Therapy [96].

Upcoming studies may also benefit from considering results of neurobiological gender differences found in precursor syndromes associated with aggression and BPD, such as conduct disorder and attention deficit hyperactivity disorder. Male patients with conduct disorder exhibited larger volumes of the anterior insula than their female counterparts [97]. Men affected with attention deficit hyperactivity disorder demonstrated reduced activation during a working memory task in frontal, temporal, subcortical, occipital and cerebellar regions relative to healthy males, whereas affected and healthy females demonstrated equivalent activations [98]. These findings underline the importance of investigating similar tasks in BPD patients.

Second, results in the general population emphasize the importance of considering different contributions to gender differences depending on the form of aggression under focus [14,15]. Understanding aggression as a complex and heterogeneous social behavior, and thoroughly differentiating between, e.g., verbal and physical forms of aggression could help to reduce inconsistencies.

Third, the potential confounding effect of comorbidities needs to be stressed. As pointed out throughout the article, male BPD patients frequently suffer from higher prevalence rates of aggression-predisposing disorders such as ASPD. Future studies should control this influence, e.g. by analyzing matched samples. The confounding influence of comorbidities also implies the use of a dimensional rather than a categorical approach to BPD psychopathology, as has been proposed by the alternative DSM-5 model of BPD [2] and recent research on BPD psychopathology [86].

\section{Funding}

This work was supported by two grants of the German Research Foundation to S. C. H. on borderline personality disorder (Clinical Research Foundation on Mechanisms of Disturbed Emotion Processing in Borderline Personality Disorder, www.kfo256.de; Schmahl et al., 2014: $\mathrm{He}$ 2660/12-1; He 2660/7-2) as well as financial support by the German Research Foundation and RuprechtKarls-Universität Heidelberg within the funding program Open Access Publishing.

\section{Competing interests}

The authors declare that they have no competing interests.

\section{Authors' contributions}

FM drafted the manuscript. $\mathrm{KB}$ and $\mathrm{SCH}$ revised and contributed to the manuscript. All authors read and approved the final manuscript.

\section{Acknowledgement}

The authors would like to cordially thank Michael S. Closkey, PhD, who supported the article with gender analyses of the Life History of Aggression questionnaire in BPD patients.

Received: 20 November 2014 Accepted: 18 March 2015

Published online: 09 April 2015

\section{References}

1. Anderson CA, Bushman BJ. Human aggression. Annu Rev Psychol. 2002;53:27-51

2. American Psychiatric Association. Diagnostic and Statistical Manual of Mental Disorders (5th Ed.). Arlington, VA: American Psychiatric Publishing; 2013.

3. Newhill CE, Eack SM, Mulvey EP. Violent behavior in borderline personality J Pers Disord. 2009;23:541-54

4. Black DW, Gunter T, Allen J, Blum N, Arndt S, Wenman G, et al. Borderline personality disorder in male and female offenders newly committed to prison. Compr Psychiatry. 2007:48:400-5.

5. Gardner DL, Leibenluft E, O'Leary KM, Cowdry RW. Self-ratings of anger and hostility in borderline personality disorder. J Nerv Ment Dis. 1991;179:157-61.

6. McCloskey MS, New AS, Siever LJ, Goodman M, Koenigsberg HW, Flory JD, et al. Evaluation of behavioral impulsivity and aggression tasks as endophenotypes for borderline personality disorder. J Psychiatr Res. 2009;43:1036-48.

7. McManus M, Alessi NE, Grapentine WL, Brickman A. Psychiatric disturbance in serious delinquents. J Am Acad Child Psychiatry. 1984;23:602-15.

8. Hines D. Borderline Personality Traits and Intimate Partner Aggression: an International Multisite, Cross-Gender Analysis. Psychol Women Q. 2008:32:290-302

9. Ostrov JM, Houston RJ. The Utility of Forms and Functions of Aggression in Emerging Adulthood: Association with Personality Disorder Symptomatology. J Youth Adolesc. 2008;37:1147-58.

10. Whisman MA, Schonbrun YC. Social consequences of borderline personality disorder symptoms in a population-based survey: marital distress, marital violence, and marital disruption. J Pers Disord. 2009;23:410-15.

11. Raine A. Features of borderline personality and violence. J Clin Psychol. 1993;49:277-81.

12. Skodol AE, Siever LJ, Livesley WJ, Gunderson JG, Pfohl B, Widiger TA. The Borderline Diagnosis II: Biology, Genetics, and Clinical Course. Biol Psychiatry. 2002;51:951-63.

13. Siever LJ, Torgersen S, Gunderson JG, Livesley WJ, Kendler KS. The Borderline Diagnosis III: Identifying Endophenotypes for Genetic Studies. Biol Psychiatry. 2002;51:964-8 
14. Archer J. Sex Differences in Aggression in Real-World Settings: A MetaAnalytic Review. Rev Gen Psychol. 2004;8:291-322.

15. Campbell A. Sex differences in direct aggression: What are the psychological mediators? Aggress Violent Behav. 2006;11:237-64.

16. Buss A, Durkee A. An Inventory for Assessing Different Kinds of Hostility. J Consult Psycho.l 1957;21:343-9.

17. Buss A, Perry M. The Aggression Questionnaire. J Pers Soc Psychol. 1992;63:452-9.

18. Straus MA, Hamby SL, Boney-Mccoy S, Sugarman DB. The Revised Conflict Tactics Scales (CTS2): Development and Preliminary Psychometric Data. J Fam Issues. 1996;17:283-316.

19. Brown GL, Ebert MH, Goyer PF, Jimerson DC, Klein WJ, Bunney WE, et al. Aggression, suicide, and serotonin: relationships to CSF amine metabolites. Am J Psychiatry. 1982;139:741-6.

20. Coccaro EF, Berman ME, Kavoussi RJ. Assessment of life history of aggression: development and psychometric characteristics. Psychiatry Res. 1997;73:147-57.

21. Kay SR, Wolkenfeld F, Murril LM. Profiles of Aggression among Psychiatric Patients I. Nature and Prevalence. J Nerv Ment Dis. 1988;176:539-46.

22. First M, Spitzer R, Gibbon M, Williams J. Structured Clinical Interview for DSM-IV (SCID). New York: Biometrics Research Department, New York State Psychiatric Institute; 1997.

23. Giancola PR, Chermack ST. Construct validity of laboratory aggression paradigms: a response to Tedeschi and Quigly (1996). Aggress Violent Behav. 1998:3:237-53.

24. Cherek DR. Effects of smoking different doses of nicotine on human aggressive behavior. Psychopharmacology (Berl). 1981;75:339-45.

25. Cherek DR, Moeller FG, Schnapp W, Dougherty D. Studies of violent and nonviolent male parolees: I. Laboratory and psychometric measurements of aggression. Biol Psychiatry. 1997;41:514-22.

26. Soloff PH, Kelly TM, Strotmeyer SJ, Malone KM, Mann JJ. Impulsivity, gender, and response to fenfluramine challenge in borderline personality disorder. Psychiatry Res. 2003;119:11-24.

27. Soloff PH, Nutche J, Goradia D, Diwadkar V. Structural brain abnormalities in borderline personality disorder: a voxel-based morphometry study. Psychiatry Res neuroimaging. 2008;164:223-36.

28. Soloff $P$, Chiappetta $L$, Mason N. Effects of serotonin-2A receptor binding and gender on personality traits and suicidal behavior in borderline personality disorder. Psychiatry Res Neuroimaging. 2014;222:140-8.

29. New AS, Hazlett EA, Newmark RE, Zhang J, Triebwasser J, Meyerson D, et al. Laboratory induced aggression: a positron emission tomography study of aggressive individuals with borderline personality disorder. Biol Psychiatry. 2009:66:1107-14

30. Silberschmidt A, Lee S, Zanarini M, Schulz SC. Gender Differences in Borderline Personality Disorder: Results From a Multinational, Clinical Trial Sample. J Pers Disord. 2015:1-11. Jan 6 [Epub ahead of print].

31. Scott LN, Stepp SD, Pilkonis PA. Prospective Associations Between Features of Borderline Personality Disorder, Emotion Dysregulation, and Aggression. Personal Disord Theory, Res Treat. 2014:5:278-88.

32. Holtzworth-Munroe A, Stuart GL. Typologies of male batterers: Three subtypes and the differences among them. Psychol Bull. 1994;116:476-97.

33. Holtzworth-Munroe A, Meehan JC, Herron K, Rehman U, Stuart GL. Testing the Holtzworth-Munroe and Stuart (1994) batterer typology. J Consult Clin Psychol. 2000;68:1000-19.

34. Shackelford TK, Goetz AT, Buss DM, Euler HA, Hoier S. When we hurt the ones we love: Predicting violence against women from men's mate retention. Pers Relatsh. 2005;12:447-63.

35. Weinstein Y, Gleason MEJ, Oltmanns TF. Borderline but Not Antisocial Personality Disorder Symptoms Are Related to Self-Reported Partner Aggression in Late Middle-Age. J Abnorm Psychol. 2012;121:692-8.

36. Banzhaf A, Ritter K, Merkl A, Schulte-Herbrüggen O, Lammers C-H, Roepke S. Gender Differences in a Clinical Sample of Patients with Borderline Personality Disorder. J Pers Disord. 2012;26:368-80.

37. Grilo C. DSM-IV axis II comorbidity with borderline personality disorder in monolingual Hispanic psychiatric outpatients. J Nerv Ment Dis. 2002;190:324-30

38. Zanarini MC, Frankenburg FR, Dubo ED, Sickel a E, Trikha A, Levin A, et al. Axis II comorbidity of borderline personality disorder. Am J Psychiatry. 1998;155:1733-9.

39. Johnson DM, Shea MT, Yen S, Battle CL, Zlotnick C, Sanislow CA, et al. Gender differences in borderline personality disorder: findings from the
Collaborative Longitudinal Personality Disorders Study. Compr Psychiatry. 2003:44:284-92.

40. Tadic A, Wagner S, Hoch J, Baskaya O, von Cube R, Skaletz C, Lieb K, Dahmen N. Gender Differences in Axis I and Axis II Comorbidity in Patients with Borderline. Psychopathology. 2009;42:257-63.

41. McCormick B, Blum N, Hansel R, Franklin JA, St John D, Pfohl B, et al. Relationship of sex to symptom severity, psychiatric comorbidity, and health care utilization in 163 subjects with borderline personality disorder. Compr Psychiatry. 2007;48:406-12.

42. Zlotnick $C$, Rothschild L, Zimmeran $M$. The role of gender in the clinical presentation of patients with borderline personality disorder. J Pers Disord. 2002;16:277-82

43. Grant BF, Chou SP, Goldstein RB, Huang B, Stinson FS, Saha TD, et al. Prevalence, correlates, disability, and comorbidity of DSM-IV borderline personality disorder: results from the Wave 2 National Epidemiologic Survey on Alcohol and Related Conditions. J Clin Psychiatry. 2008;69:533-45.

44. Barrachina J, Pascual JC, Ferrer M, Soler J, Rufat MJ, Andión O, et al. Axis ॥ comorbidity in borderline personality disorder is influenced by sex, age, and clinical severity. Compr Psychiatry. 2011;52:725-30.

45. Dougherty D, Bjork JM, Huckabee HC, Moeller FG, Swann AC. Laboratory measures of aggression and impulsivity in women with borderline personality disorder. Psychiatry Res. 1999;85:315-26.

46. Bettencourt BA, Miller N. Gender differences in aggression as a function of provocation: a meta-analysis. Psychol Bull. 1996;119:422-47.

47. Moffitt TE. The new look of behavioral genetics in developmental psychopathology: gene-environment interplay in antisocial behaviors. Psychol Bull. 2005;131:533-54.

48. Jaffee SR, Strait LB, Odgers CL. From correlates to causes: can quasi-experimental studies and statistical innovations bring us closer to identifying the causes of antisocial behavior? Psychol Bull. 2012;138:272-95.

49. Patterson GR, DeBaryshe BD, Ramsey E. A developmental perspective on antisocial behavior. Am Psychol. 1989:44:329-35.

50. Campbell SB, Pierce EW, Moore G, Marakovitz S, Newby K. Boys' externalizing problems at elementary school age: Pathways from early behavior problems, maternal control, and family stress. Dev Psychopathol. 1996:8:701-19.

51. Siever LJ. Neurobiology of aggression and violence. Am J Psychiatry 2008:165:429-42.

52. Krakowski M. Violence and Serotonin: Influence of Impulse Control, Affect Regulation, and Social Functioning. J neuropsychiatry Clin. 2003;15:294-305.

53. Davidson RJ. Dysfunction in the Neural Circuitry of Emotion Regulation-A Possible Prelude to Violence. Science. (80-) 2000, 289:591-594.

54. Gregg TR, Siegel A. Brain structures and neurotransmitters regulating aggression in cats: implications for human aggression. Prog Neuropsychopharmacol Biol Psychiatry. 2001;25:91-140

55. Blair R. Considering anger from a cognitive neuroscience perspective. Wiley Interdiscip Rev Cogn Sci. 2012;3:65-74.

56. Beauchaine TP, Klein DN, Crowell SE, Derbidge C, Gatzke-Kopp L. Multifinality in the development of personality disorders: a Biology x Sex x Environment interaction model of antisocial and borderline traits. Dev Psychopathol. 2009:21:735-70.

57. Caspi A, McClay J, Moffitt TE, Mill J, Martin J, Craig IW, et al. Role of genotype in the cycle of violence in maltreated children. Science. 2002;297:851-4

58. Hazlett EA, New AS, Newmark R, Haznedar MM, Lo JN, Speiser LJ, et al. Reduced anterior and posterior cingulate gray matter in borderline personality disorder. Biol Psychiatry. 2005;58:614-23.

59. Minzenberg MJ, Fan J, New AS, Tang CY, Siever LJ. Frontolimbic structural changes in borderline personality disorder. J Psychiatr Res. 2008;42:727-33.

60. Brambilla P, Soloff PH, Sala M, Nicoletti MA, Keshavan MS, Soares JC Anatomical MRI study of borderline personality disorder patients. Psychiatry Res. 2004;131:125-33.

61. Bertsch K, Grothe M, Prehn K, Vohs K, Berger C, Hauenstein K, et al. Brain volumes differ between diagnostic groups of violent criminal offenders. Eur Arch Psychiatry Clin Neurosci. 2013:263:593-606.

62. Völlm B, Zhao L, Richardson P. A voxel-based morphometric MRI study in men with borderline personality disorder: preliminary findings. Crim Behav Ment Heal. 2009;72:64-72.

63. Perez-Rodriguez MM, Hazlett EA, Rich EL, Ripoll LH, Weiner DM, Spence N, et al. Striatal activity in borderline personality disorder with comorbid intermittent explosive disorder : Sex differences. J Psychiatr Res. 2012;46:797-804. 
64. Ernst M, Fudge JL. A developmental neurobiological model of motivated behavior: anatomy, connectivity and ontogeny of the triadic nodes. Neurosci Biobehav Rev. 2009;33:367-82.

65. Houk J, Wise S. Distributed modular architectures linking basal ganglia, cerebellum, and cerebral cortex: their role in planning and controlling action. Cereb Cortex. 1995;5:95-110.

66. Frank M. Dynamic dopamine modulation in the basal ganglia: a neurocomputational account of cognitive deficits in medicated and nonmedicated Parkinsonism. J Cogn Neurosci. 2005;17:51-72.

67. Soloff PH, Meltzer CC, Becker C, Greer PJ, Constantine D. Gender differences in a fenfluramine-activated FDG PET study of borderline personality disorder. Psychiatry Res. 2005;138:183-95.

68. Prehn K, Schulze L, Rossmann S, Berger C, Vohs K, Fleischer M, et al. Effects of emotional stimuli on working memory processes in male criminal offenders with borderline and antisocial personality disorder. World J Biol Psychiatry. 2013;14:71-8.

69. Niedtfeld I, Schulze L, Kirsch P, Herpertz SC, Bohus M, Schmahl C. Affect regulation and pain in borderline personality disorder: a possible link to the understanding of self-injury. Biol Psychiatry. 2010;68:383-91.

70. Lang P, Bradley M, Cuthbert B. International Affective Picture System (IAPS): Digitized Photographs, Instruction Manual and Affective Ratings. Technical Report A-6. Gainesville, FL: University of Florida; 2005.

71. McClure EB, Monk CS, Nelson EE, Zarahn E, Leibenluft E, Bilder RM, et al. A developmental examination of gender differences in brain engagement during evaluation of threat. Biol Psychiatry. 2004;55:1047-55.

72. Goldstein J, Seidman L, Horton N. Normal sexual dimorphism of the adult human brain assessed by in vivo magnetic resonance imaging. Cereb Cortex. 2001;11:490-7.

73. Hollander E, Stein D. Serotonergic sensitivity in borderline personality disorder: preliminary. Am J Psychiatry. 1994;151:277-80.

74. Martial J, Paris J, Leyton M, Zweig-Frank H, Schwartz G, Teboul E, et al. Neuroendocrine study of serotonin function in female borderline personality disorder patients: a pilot study. Biol Psychiatry. 1997;42:737-9.

75. Rinne T, Westenberg HG, den Boer J a, van den Brink W. Serotonergic blunting to meta-chlorophenylpiperazine (m-CPP) highly correlates with sustained childhood abuse in impulsive and autoaggressive female borderline patients. Biol Psychiatry. 2000;47:548-56.

76. Verona E, Joiner TE, Johnson F, Bender TW. Gender specific geneenvironment interactions on laboratory-assessed aggression. Biol Psychol. 2006;71:33-41.

77. Crowell SE, Beauchaine TP, McCauley E, Smith CJ, Vasilev C a, Stevens AL. Parent-child interactions, peripheral serotonin, and self-inflicted injury in adolescents. J Consult Clin Psychol. 2008;76:15-21.

78. Coccaro EF, Kavoussi RJ, Hauger RL, Cooper TB, Ferris CF. Cerebrospinal fluid vasopressin levels: correlates with aggression and serotonin function in personality-disordered subjects. Arch Gen Psychiatry. 1998;55:708-14.

79. Yildirim BO, Derksen JJL. A review on the relationship between testosterone and life-course persistent antisocial behavior. Psychiatry Res. 2012;200:984-1010.

80. Carré JM, McCormick CM, Hariri AR. The social neuroendocrinology of human aggression. Psychoneuroendocrinology. 2011;36:935-44.

81. Archer J, Graham-Kevan N, Davies M. Testosterone and aggression: A reanalysis of Book, Starzyk, and Quinsey's (2001) study. Aggress Violent Behav. 2005;10:241-61.

82. Coccaro EF, Beresford B, Minar P, Kaskow J, Geracioti T. CSF testosterone: Relationship to aggression, impulsivity, and venturesomeness in adult males with personality disorder. J Psychiatr Res. 2007;41:488-92.

83. Roepke S, Ziegenhorn A, Kronsbein J, Merkl A, Bahri S, Lange J, et al. Incidence of polycystic ovaries and androgen serum levels in women with borderline personality disorder. J Psychiatr Res. 2010;44:847-52.

84. Bertsch K, Schmidinger I, Neumann ID, Herpertz SC. Reduced plasma oxytocin levels in female patients with borderline personality disorder. Horm Behav. 2013;63:424-9.

85. Bushman BJ, Anderson CA. Is it time to pull the plug on the hostile versus instrumental aggression dichotomy? Psychol Rev. 2001;108:273-9.

86. Mancke F, Herpertz SC, Bertsch K. Aggression in borderline personality disorder - a multidimensional model. Personal Disord Theory, Res Treat 2015, http://dx.doi.org/10.1037/per0000098, in press.

87. Coccaro EF, Sripada CS, Yanowitch RN, Phan KL. Corticolimbic function in impulsive aggressive behavior. Biol Psychiatry. 2011;69:1153-9.
88. Oquendo MA, Mann JJ. The biology of impulsivity and suicidality. Psychiatr Clin North Am. 2000;23:11-25.

89. Plichta MM, Scheres $A$. Ventral-striatal responsiveness during reward anticipation in ADHD and its relation to trait impulsivity in the healthy population: a meta-analytic review of the fMRI literature. Neurosci Biobehav Rev. 2014;38:125-34.

90. Soloff PH, Meltzer C, Becker C. Impulsivity and prefrontal hypometabolism in borderline personality disorder. Psychiatry Res Neuroimaging. 2003;123:153-63.

91. Soloff PH, White R, Diwadkar VA. Impulsivity, aggression and brain structure in high and low lethality suicide attempters with borderline personality disorder. Psychiatry Res Neuroimaging. 2014;222:131-9.

92. Barnow S, Herpertz SC, Spitzer C, Stopsack M, Preuss UW, Grabe HJ, et al. Temperament and character in patients with borderline personality disorder taking gender and comorbidity into account. Psychopathology. 2007;40:369-78

93. Strüber D, Lück M, Roth G. Sex, aggression and impulse control: an integrative account. Neurocase. 2008;14:93-121.

94. Diekhof EK, Geier K, Falkai P, Gruber O. Fear is only as deep as the mind allows: a coordinate-based meta-analysis of neuroimaging studies on the regulation of negative affect. Neuroimage. 2011;58:275-85.

95. Coccaro EF, Lee RJ, Kavoussi RJ. A Double-Blind, Randomized, PlaceboControlled Trial of Fluoxetine in Patients With Intermittent Explosive Disorder. J Clin Psychiatry. 2009;70:653-62.

96. Linehan MM. Cognitive Behavioral Treatment of Borderline Personality Disorder. New York Guilford Press; 1993.

97. Fairchild G, Hagan CC, Walsh ND, Passamonti L, Calder AJ, Goodyer IM. Brain structure abnormalities in adolescent girls with conduct disorder. J Child Psychol Psychiatry. 2013;54:8.

98. Valera E, Brown A. Sex differences in the functional neuroanatomy of working memory in adults with ADHD. Am J Psychiatry. 2010;167:86-94.

\section{Submit your next manuscript to BioMed Central and take full advantage of:}

- Convenient online submission

- Thorough peer review

- No space constraints or color figure charges

- Immediate publication on acceptance

- Inclusion in PubMed, CAS, Scopus and Google Scholar

- Research which is freely available for redistribution 